\title{
Production of Low Fat Cheddar Cheese Made Using Exopolysaccharide-Producing Cultures and Selected Ripening Cultures
}

\author{
Morsi El Soda \\ Department of Dairy Science and Technology, Alexandria University, Alexandria, Egypt \\ Email: morsi elsoda@hotmail.com
}

Received 23 June 2014; revised 18 July 2014; accepted 22 August 2014

Copyright (C) 2014 by author and Scientific Research Publishing Inc.

This work is licensed under the Creative Commons Attribution International License (CC BY). http://creativecommons.org/licenses/by/4.0/

(c) (i) Open Access

\begin{abstract}
Low fat cheeses often suffer from undesirable texture and flavor. The objective of this study is to improve the yield, texture, flavor and quality of low fat Cheddar cheese during ripening using exopolysaccharide-producing lactobacilli and ripening cultures. The article represents one of the first attempts to tackle both texture and flavor at the same time. The study reveals the effect of aging on the texture and flavor of low fat Cheddar cheese over a ripening period of six months. The cheese manufactured with a modified protocol using EPS-producing cultures and ripening cultures showed higher values for moisture content $(45 \%)$ and yield $(9.4 \%)$ when compared to cheese manufactured with the conventional procedure and without the addition of EPS-producing cultures and ripening cultures $(37.7 \%)$ and $(4.9 \%)$ respectively. The obtained results indicated a $70 \%$ decrease in the fat content of the cheese. Texture profile analysis (TPA) indicated that the hardness, the cohesiveness, the springiness, the gumminess and the chewiness of the cheeses made using the EPS-producing cultures decreased with aging. The texture of the ripened low fat cheese made using EPS-producing cultures was described as chewy, springy, cohesive and smooth. The use of the ripening cultures resulted in the elimination of the bitter flavor defect which is a common problem in low fat Cheddar.
\end{abstract}

\section{Keywords}

Exopolydaccharide, Ripening Culture, Low Fat Cheddar

\section{Introduction}

Over consumption of dietary fat is associated with various chronic illnesses [1]. This association has created in-

How to cite this paper: El Soda, M. (2014) Production of Low Fat Cheddar Cheese Made Using Exopolysaccharide-Producing Cultures and Selected Ripening Cultures. Advances in Microbiology, 4, 986-995. 
creased consumer awareness and an increase in the demand for low-fat foods, including cheese [2]. However, the consumption of low/reduced-fat cheese is still low [3]-[6]. In fact, low-fat cheeses have low intensity of typical flavor and, may develop a bitter off-flavor and hard, rubbery, dry and grainy texture [7]-[9].

Difficulties arise when attempts are made to produce low fat variants of cheeses that are popular and established in the market as full fat varieties. In producing low fat variants of standard fat cheeses such as Cheddar, processing parameters must be altered substantially in order to produce an acceptable texture and flavor.

Different strategies were described to overcome both texture and flavor defects, which include the retention of higher moisture in the curd, which can partially replace fat and improve texture through cutting into larger cubes, lowering the cooking temperature, draining and milling at a higher $\mathrm{pH}$. Stabilizers and fat replacers were also used to improve texture. This practice was often followed by off flavor development.

Exopolysaccharides-producing lactic acid bacteria (EPS-producing cultures) have been used to improve product functionality in the dairy industry by binding free water. They have been suggested for low fat Cheddar cheesemaking for several reasons. They have the ability to bind water and to increase moisture; exopolysaccharides increase moisture retention by water binding or entrapment within their 3-dimensional network. In addition, EPS seem to act as nuclei for the formation of large pores in cheese; they also increase the viscosity of the aqueous phase in cheese and modify its flow characteristics. In addition, EPS interfere with protein-protein interactions physically or through their interaction with proteins. Several studies highlighted the positive effect of EPS-producing cultures on the physical and functional properties of reduced fat Cheddar cheese [10]-[13]. Bitterness is a common defect in reduced fat Cheddar cheeses and reported to develop after 2 to 3 months of ripening of cheese made with an EPS-producing culture [14]. Because the EPS-positive strain was not a typical Cheddar cheese starter culture, it did not have an adequate peptidolytic system to further hydrolyze the bitter peptides to amino acids. Most, if not all, typical Cheddar cheese starters do not produce EPS. Special cultures had been suggested to overcome the flavor defects, bitterness, and unclean flavors [15]. However, it still remains a challenge to reduce fat and maintain the texture and flavor of a comparable full fat cheese.

Adjunct cultures are nonstarter lactic acid bacteria consisting mainly of Lactobacillus sp., which are used in addition to a standard mesophilic starter to improve and to enhance the flavor of cheese. However, for the role of the adjunct in cheese ripening to be maximized, the intracellular enzymes must be released from the cells into the cheese matrix, which explains much of the attention given to cell autolysis during ripening. There has been considerable interest in using defined strains of nonstarter lactic acid bacteria as adjunct cultures to accelerate and improve flavor and texture development during cheese ripening [16].

The objective of this study is to introduce three different strategies in order to reach a low fat Cheddar exhibiting sensory characteristics similar to the full fat product and can be cited as follows: 1) Bring changes to the manufacturing process including size of cubes after cutting, cooking temperature, speed and rate of stirring, the use of higher $\mathrm{pH}$ during the cheddaring and milling processes; 2) Addition of EPS-producing cultures described as ropy and capsular; 3) Addition of ripening cultures exhibiting a complex peptidase system.

\section{Materials and Methods}

\subsection{Bacterial Strains}

A starter mixture composed of the following groups of microorganisms: 1) The acid producing culture R704 composed of (Lactococcus lactis subsp lactis and Lactococcus lactis subsp cremoris) obtained from Chr. Hansen (Hørsholm, Denmark); 2) The EPS-producing cultures composed of (Lactobacillus delbrueckii subsp lactis and Lactobacillus paraplantarum were used for the manufacture of low fat cheddar cheese; 3) The ripening cultures composed of two Lactobacillus paracasei subsp paracasei. The EPS-producing cultures and the ripening cultures were selected, genetically identified and phenotypically characterized in the laboratory of the biochemistry of dairy microorganisms, Alexandria University.

\section{Strain Characteristics}

The exopolysaccharides-producing lactobacilli cultures were classified as capsular, ropy and unattached. When a colony was touched with a wire inoculating loop strings of 11 and $9 \mathrm{~mm}$ were formed by both Lactobacillus delbrueckii subsp lactis and Lactobacillus paraplantarum respectively (unpublished data).

The ripening cultures selected for their complex peptide hydrolase system composed of an aminopeptidase $\mathrm{N}$, three dipeptidasesan X-prolyldipeptidyl-peptidase as well as a carboxypeptidase and a specific endopeptidase. In 
addition to a general caseinolytic activity hydrolyzing $\alpha \mathrm{S} 1$ and $\beta$-casein, several esterases releasing $\mathrm{C} 4$, C6 and C8 fatty acids were also detected in these strains (unpublished data).

\subsection{Cheesemaking}

Cheese was made in the Cheese Research Laboratory, Department of Dairy Science and Technology, Alexandria University. Raw cow's milk obtained from the university dairy farm was standardized to $1 \%$ fat in milk in the case of low fat cheese and 3\% fat for full fat cheese. The milk was then pasteurized at $74^{\circ} \mathrm{C}$ for 15 sec and cooled to $30^{\circ} \mathrm{C}$ using an Actini model Acti-Joule pasteurizer. The cheese cultures consisting of the commercial starter, the two EPS-producing lactobacilli and the two ripening cultures were added according to the following six treatments:

1) FFC = control full fat cheese made using the conventional procedure in the presence of the commercial starter culture.

2) LFC1 = low fat cheese made using the conventional procedure in the presence of the commercial starter culture.

3) LFC2 = low fat cheese made using the modified protocol in the presence of the commercial starter culture.

4) $\mathrm{LFC}+\mathrm{Rp}=$ low fat cheese made using the modified protocol in the presence of the commercial starter culture and the ripening cultures.

5) EPSLFC = low fat cheese made using the modified protocol in the presence of the commercial starter culture and the EPS-producing lactobacilli.

6) EPSLFC + Rp = low fat cheese made using the modified protocol in the presence of the commercial starter culture, the EPS-producing lactobacilli as well as the ripening cultures.

Computerized mini-cheesemaking vats (INRA, Poliny, France) were used for cheesemaking. After 45 - 60 min of the addition of the previous mixture of cultures to milk at $30^{\circ} \mathrm{C}$, the $\mathrm{pH}$ was dropped $(0.1 \%)$. Calcium Chloride (0.02\%) was then added. sufficient rennet (Chymax, Chr. Hansen, Hørsholm, Denmark) was added to coagulate the milk in $30 \mathrm{~min}$. The coagulum was then cut gently for 2 to $6 \mathrm{rpm}$ to hold more moisture; the cubes are then cooked in the whey for 60 min by increasing the temperature to $36^{\circ} \mathrm{C}$ and the curds were held at $36^{\circ} \mathrm{C}$ for $20 \mathrm{~min}$. After whey drainage, the curd was cheddared for approximately $60 \mathrm{~min}$ at $36^{\circ} \mathrm{C}$ and then milled at $\mathrm{pH}$ 5.6. The curd was salted to reach $1.5 \%$ in the finished cheese and pressed over night. Cheese is ripened at $8^{\circ} \mathrm{C}, 85 \%$ relative humidity for 6 months. Samples from each treatment were analyzed in triplicate at zero, 1, 30, 60, 90, 120, 180 days. The full fat Cheddar cheese control was made according to the conventional procedure [17] and could be summarized as follows: full fat Cheddar cheese was made from $3 \%$ fat. Pasteurized milk was warmed to $30^{\circ} \mathrm{C}$ and inoculated with the starter culture. Rennet was then added to coagulate the milk in 30 min. The coagulum was then cut and the temperature gradually raised to $39^{\circ} \mathrm{C}\left(0.2^{\circ} \mathrm{C} / \mathrm{min}\right)$. Whey was drained and the curd cheddared for 110 min until the $\mathrm{pH}$ reached $5.3 \pm 0.5$, it was then milled, dry salted and pressed overnight. Cheese is ripened at $8^{\circ} \mathrm{C}, 85 \%$ relative humidity.

\subsection{Chemical Analysis}

Cheeses were analyzed for moisture using the moisture analyzer (Mettler Toledo model HR73), salt content was determined using the chloride meter (Jenway, England, UK) and total protein by Kjeldahl method. The pH of cheeses was measured in slurry prepared by macerating $20 \mathrm{~g}$ of cheese in $20 \mathrm{ml}$ of deionized water using a glass electrode (Jenway, 5303). The percent fat was also considered [18]. The cheese yield was calculated as the mass ratio between the curds obtained after the pressing stage and the weight of milk.

\subsection{Texture Profile Analysis (TPA)}

Textural properties of cheese were evaluated using a texture analyzer (TA1000, Lab Pro (FTC TMS-Pro), USA). Cheese samples were cut into $30 \mathrm{~mm}^{3}$ cubes, samples were allowed to stand at ambient temperature for at least $1 \mathrm{~h}$ before testing. A two-bite penetration test was performed and operated at a crosshead speed $50 \mathrm{~mm} / \mathrm{sec}$. Hardness, cohesiveness, springiness, gumminess and chewiness were evaluated in triplicate [19] [20].

\subsection{Sensory Evaluation}

Ten experienced panelists were provided with $20 \mathrm{~mm}^{3}$ cubes of each cheese. The cheeses were tempered at $25^{\circ} \mathrm{C}$ 
for $1 \mathrm{~h}$ and were served at this temperature. Deionized water was given to panelists to clean their palates between each sample and reference cheese was provided into the tested samples. Samples were presented in identical containers labeled with a random number. The cheese samples were assessed for the following flavor attributes: unclean and bitter as well as the following cheese texture attributes: crumbly, firmness, smooth and springy. Scores of 1 considered low, while 5 and 9 indicated medium and high attribute respectively.

\subsection{Statistical Analysis}

All samples were carried out in duplicate and all analysis was done in triplicate. Statistical analyses were performed with Fisher's least-significant differences and LSD procedures available with the SAS software package, 2008 with a considered significant at $P<0.05$. Significant differences between treatments were tested by ANOVA.

\section{Results and Discussion}

\subsection{Chemical Composition}

The obtained results concerning the composition of Cheddar cheese (Table 1) revealed that decreasing the fat content of cheese milk resulted in an increase in cheese moisture and protein and a decrease in cheese yield. These observations are in agreement with the data reported by several authors [10]-[12] [21]-[23].

Preliminarily data revealed that the best manufacturing conditions in the presence of selected EPS producing cultures and ripening cultures are larger curd size after cutting, lower scalding temperature at $36^{\circ} \mathrm{C}$, lower stiring speed, higher drainage, cheddaring $\mathrm{pH}$ at (5.6) and lower pressing force. Low fat cheese made using the modified protocol showed an increase of $1.2 \%$ in yield and $2.3 \%$ moisture when compared to the low fat cheese made using the conventional protocol. Previous contributions [24]-[26] revealed that lowering the cooking or scalding temperatures, reducing the stirring speed and milling at high $\mathrm{pH}$ can be used to increase the moisture content in low fat cheese. When EPS-producing cultures were added during the making of low fat cheese using the modified protocol, the resultant cheese exhibited higher moisture and yield than low fat made without the addition of the EPS-producing cultures.

Table 1 showed that the values of the moisture and the yield of the LFC1 were $40 \% \pm 0.3$ and $6.1 \%$ respectively. Addition of the EPS-producing cultures led to a significant increase of both moisture and yield which reached $45 \% \pm 0.5$ and $9.4 \%$ respectively. The yield value of the EPSLFC $+\mathrm{Rp}$ is close to that of the full fat cheese.

Our results revealed that the addition of our selected combination of EPS-producing cultures and ripening cultures and the modification of the manufacturing protocol affected the yield of low fat Cheddar cheese. The fat level of the EPS low fat Cheddar cheese is (10\%) and (32\%) in the case of the full fat cheese which indicated a $70 \%$ decrease in the fat content of the cheese. No significant differences in $\mathrm{pH}$ were found between EPS low fat cheeses and full fat after four months of ripening.

Table 1. Chemical analysis and cheese yield after manufacture ${ }^{1}$.

\begin{tabular}{|c|c|c|c|c|c|c|}
\hline Treatments $^{2}$ & $\mathrm{pH}$ & $\begin{array}{c}\text { Moisture \% } \\
\text { wt/wt }\end{array}$ & $\begin{array}{l}\text { Fat } \% \\
\text { wt/wt }\end{array}$ & $\begin{array}{l}\text { Salt \% } \\
\text { wt/wt }\end{array}$ & $\begin{array}{l}\text { Protein \% } \\
\text { wt/wt }\end{array}$ & Yield \% \\
\hline FFC & $5.14^{\mathrm{a}}$ & $37.14^{\mathrm{c}}$ & $32.1^{\mathrm{a}}$ & $1.52^{\mathrm{a}}$ & $27.23^{d}$ & $10.2^{\mathrm{a}}$ \\
\hline LFC1 & $5.27^{\mathrm{a}}$ & $37.71^{\mathrm{c}}$ & $10.15^{\mathrm{b}}$ & $1.56^{\mathrm{a}}$ & $39.15^{\mathrm{a}}$ & $4.9^{\mathrm{e}}$ \\
\hline LFC2 & $5.29^{\mathrm{a}}$ & $40.02^{b}$ & $10.12^{\mathrm{b}}$ & $1.54^{\mathrm{a}}$ & $37.12^{\mathrm{b}}$ & $6.1^{\mathrm{d}}$ \\
\hline $\mathrm{LFC}+\mathrm{AJ}$ & $5.23^{\mathrm{a}}$ & $40.26^{b}$ & $10.41^{\mathrm{b}}$ & $1.54^{\mathrm{a}}$ & $37.59^{b}$ & $8.7^{c}$ \\
\hline EPSLFC & $5.27^{\mathrm{a}}$ & $45.28^{\mathrm{a}}$ & $9.8^{\mathrm{c}}$ & $1.53^{\mathrm{a}}$ & $34.22^{c}$ & $9.2^{\mathrm{b}}$ \\
\hline EPSLFC + AJ & $5.20^{\mathrm{a}}$ & $45.73^{\mathrm{a}}$ & $9.8^{\mathrm{c}}$ & $1.53^{\mathrm{a}}$ & $34.57^{c}$ & $9.4^{\mathrm{b}}$ \\
\hline
\end{tabular}

${ }^{\mathrm{a}-\mathrm{e}}$ Mean \pm standard deviation followed by the same letter's are not significant, but different letters are significant according to LSD procedure $(P<$ $0.05)$. ${ }^{1}$ Samples were taken after pressing; ${ }^{2} \mathrm{FFC}=$ control full fat cheese made using the conventional procedure in the presence of the commercial starter culture; LFC1 = low fat cheese made using the conventional procedure in the presence of the commercial starter culture; LFC2 = low fat cheese made using the modified protocol in the presence of the commercial starter culture; LFC + Rp $=$ low fat cheese made using the modified protocol in the presence of the commercial starter culture and the ripening cultures; EPSLFC = low fat cheese made using the modified protocol in the presence of the commercial starter culture and the EPS-producing lactobacilli; EPSLFC + Rp = low fat cheese made using the modified protocol in the presence of the commercial starter culture, the EPS-producing lactobacilli as well as the ripening cultures. 


\subsection{Texture Analysis}

In order to study the impact of the EPS producing cultures, ripening cultures and the changes in the manufacturing conditions on the textural characteristics of low fat Cheddar cheese, the following parameters were considered.

\subsubsection{Hardness}

The results describing the hardness of full fat and low fat cheeses revealed significantly higher values in low fat cheese manufactured using the conventional procedure which led to an extremely hard cheese (Figure 1(a)). These observations are comparable to previous findings [21] [27]. Modifications of the cheesemaking protocol led to a slight decrease in hardness that can be attributed to the increase in the moisture level of the cheese. On the other hand, addition of the EPS-producing cultures (Lactobacillus delbrueckii subsp lactis and Lactobacillus paraplantarum) was the major contributor to hardness decrease. In fact a 70\% decrease in hardness was observed in EPSLFC and EPSLFC + Rp after cheesemaking when compared to LFC2 (Figure 1(a)). These observations are comparable to previous studies that highlighted the positive effect of EPS-producing cultures on the physical and functional properties of reduced fat Cheddar cheeses [10]-[13]. During the first three months of ripening, a decrease in hardness was observed in all cheeses followed by an increase of all treatments after four months of ripening; this may be due to the breakdown of the casein and the increase of protein-protein interactions. Creamer and Olson [28] attributed the increase in the hardness values during ripening to the increase of the concentration of free amino acids and small peptides formed by casein hydrolysis, which be able to bind free water molecules and consequently increase the strength of the casein matrix and thus increase the resistance of cheese to deformation. A similarity was observed between the hardness of FFC, EPSLFC and EPSLFC + Rp during ripening; this is probably due to the proteolytic activity of the added adjunct cultures during ripening. After six months of ripening, EPSLFC + AJ showed firm but cohesive texture when compared to FFC which exhibited crumbly texture; these results indicate the effective impact of the EPS-producing cultures to modify the hardness of low fat Cheddar cheese. Similar observations were previously reported [11] [12] which showed that EPS may have an important role in modifying reduced fat Cheddar cheese textural properties. Madkor,
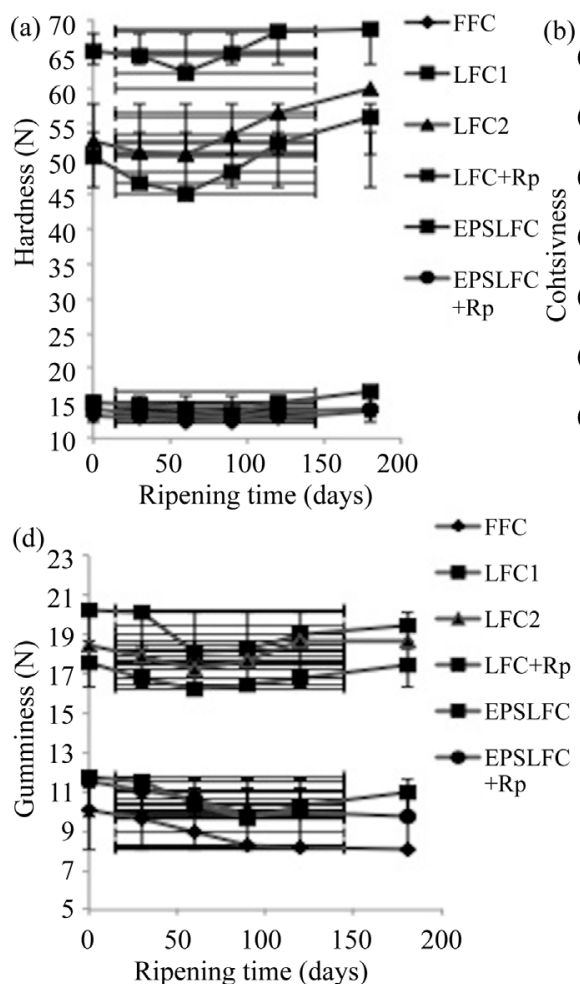

$+\mathrm{Rp}$ (b) 0.9$$
0.4
$$

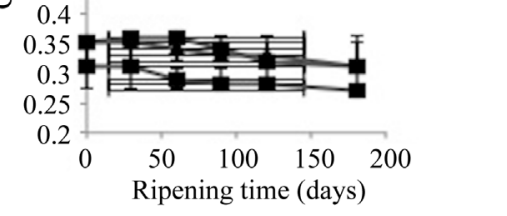

(e) 80

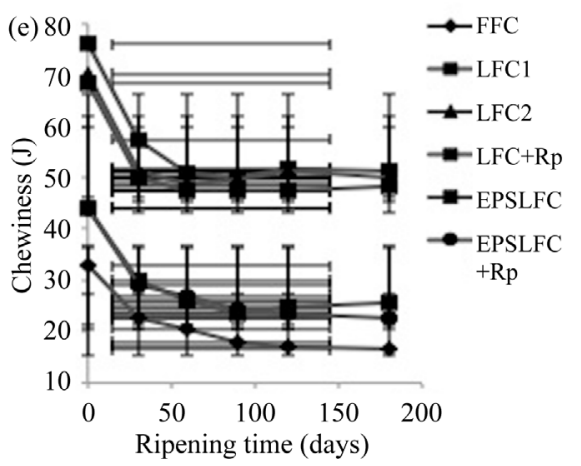

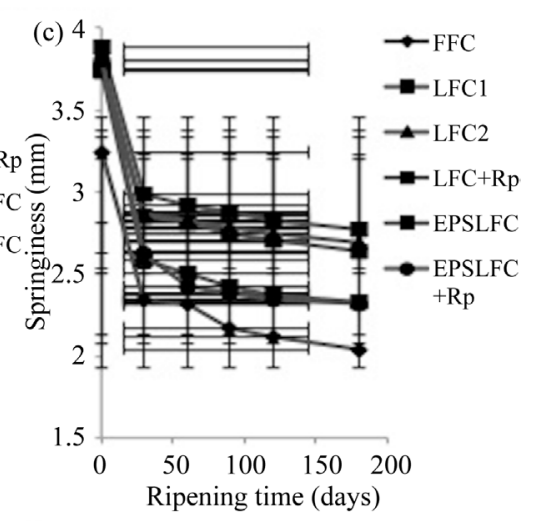

Figure 1. Evaluation of texture parameters over ripening. 
Tong, and El Soda [29] reported that the higher proteolysis rates of some adjunct treated cheeses may be associated with the decrease in firmness particularly in low fat cheese. Enhanced breakdown of the casein matrix especially $\alpha$-casein has been associated with improved texture and smooth body in reduced fat cheese.

\subsubsection{Cohesiveness}

The evaluation of cohesiveness in the different treatment is shown in (Figure 1(b)). LFC2 exhibited better cohesiveness when compared to LFC1. Addition of the EPS-producing cultures had a positive impact on the cohesiveness of low fat cheeses. EPSLFC and EPSLFC + Rp cheeses exhibited significantly higher values of cohesiveness when compared to LFC1 and LFC2. During ripening, a decrease in cohesiveness in all treatment was observed; this is due to the decrease in moisture content and the proteolysis during ripening. Cheese cohesiveness was shown to decrease as cheese moisture content decreases [30]. Cheese cohesiveness is inversely related to cheese proteolysis, with a trend of decreasing with increasing proteolysis [31]. The EPSLFC and EPSLFC + Rp showed more cohesive than FFC after 4 and 6 months of ripening, this is be probably due to the proteolysis caused by the addition of the two Lactobacillus paracasei subsp paracasei strains. Proteolysis disrupts the structural integrity of the protein matrix, leading to reduced cohesiveness [11].

\subsubsection{Springiness}

Results of springiness for the full fat and different low fat cheese treatments are illustrated in (Figure 1(c)). Low fat cheese made using the conventional protocol exhibited higher values of springiness when compared to the full fat which is in agreement with Beal and Mittal [27], who found that as fat in Cheddar decreased, hardness, springiness and cohesiveness increased. The use of the modified protocol and the EPS-producing cultures in the making of the low fat cheese decreased the values of springiness. After the first month, a sharp decrease in springiness was measured in all treatments followed by a decrease in all treatments during the ripening period. This decrease in springiness values could be referred to the hydrolysis of the para $\kappa$-caseinate molecules, which are responsible for the springiness of cheese curd [32]. EPS low fat treated cheese showed springier than FFC. Costa et al. [23] reported that reduced fat Cheddar cheese exhibits more springiness that the full fat product.

\subsubsection{Gumminess}

The gumminess of the different treatment is illustrated in (Figure 1(d)). The obtained data reveals significant differences between the cheeses made with EPS-producing cultures (EPSLFC and EPSLFC + Rp) and the non EPS treated cheese (LFC1, LFC2 and LFC + Rp). EPS treated cheeses had lower gumminess values very close to FFC. These results were in agreement with previous studies [11].

\subsubsection{Chewiness}

Chewiness could be defined as the energy required chewing a solid food product to a state where it is ready for swallowing [19] [20]. As a general rule, FFC and EPS treated cheeses (EPSLFC and EPSLFC + Rp) showed the lower chewiness values than other treatments (Figure 1(e)). The highest chewiness values were observed in the case of LFC1 and LFC2. A sharp decrease for all treatments was observed after the first month of ripening, this phenomenon could not be detected for FFC. Similar observations were reported [11]. During ripening a decrease in chewiness was observed in all cheeses. There is a correlation between cheese hardness and chewiness, harder cheese is more difficult to chew [26].

\subsection{The Sensory Evaluation}

The sensory evaluation results indicated the presence of defects in both texture and flavor in the case of Cheddar cheese manufactured using the conventional protocol (Table 2). The texture can be described as rubbery and extremely firm. A pronounced bitter flavor defect as well as an unclean flavor was detected during ripening. Many reports have also shown that when the fat content of cheese is progressively reduced, the cheese develops an undesirable firm, weak, rubbery texture and flavor notes that are atypical for the corresponding full fat product [4] [21]. Numerous strategies have been applied to improve the texture of low fat cheese, which has been reviewed in several occasions [10] [11] [29]. However, it still remains a challenge to reduce fat and maintain the texture of a comparable full fat cheese. In ripened cheeses such as low fat Cheddar, an imbalance in flavor dur- 
Table 2. Sensory evaluation of Cheddar cheeses during ripening.

\begin{tabular}{|c|c|c|c|c|c|c|c|}
\hline \multirow{3}{*}{ Treatment ${ }^{1}$} & \multirow{3}{*}{$\begin{array}{l}\text { Ripening } \\
\text { period } \\
\text { (months) }\end{array}$} & \multicolumn{6}{|c|}{ Sensory parameters } \\
\hline & & \multicolumn{2}{|c|}{ Flavor parameters } & \multicolumn{4}{|c|}{ Texture parameters } \\
\hline & & Unclean & Bitter & Crumbly & Firmness & Smooth & Springy \\
\hline \multirow{3}{*}{ FFC } & 2 & $0.1^{\mathrm{c}, \mathrm{e}}$ & $0.5^{\mathrm{b}, \mathrm{c}}$ & $2^{a, b}$ & $1.5^{\mathrm{a}, \mathrm{c}}$ & $7^{\mathrm{b}, \mathrm{b}}$ & $3^{\mathrm{b}, \mathrm{c}}$ \\
\hline & 4 & $0.6^{\mathrm{b}, \mathrm{d}}$ & $0.5^{\mathrm{b}, \mathrm{c}}$ & $2^{\mathrm{b}, \mathrm{b}}$ & $0.7^{\mathrm{b}, \mathrm{d}}$ & $9^{\mathrm{a}, \mathrm{a}}$ & $5^{\mathrm{a}, \mathrm{b}}$ \\
\hline & 6 & $0.7^{\mathrm{a}, \mathrm{d}}$ & $0.7^{\mathrm{a}, \mathrm{c}}$ & $3^{\mathrm{b}, \mathrm{b}}$ & $0.7^{\mathrm{b}, \mathrm{d}}$ & $9^{\mathrm{a}, \mathrm{a}}$ & $5^{\mathrm{a}, \mathrm{b}}$ \\
\hline \multirow{3}{*}{ LFC1 } & 2 & $2.8^{\mathrm{c}, \mathrm{d}}$ & $2^{c, b}$ & $8^{\mathrm{a}, \mathrm{a}}$ & $6^{\mathrm{b}, \mathrm{b}}$ & $1^{\mathrm{a}, \mathrm{d}}$ & $0^{\text {a.d }}$ \\
\hline & 4 & $5.6^{\mathrm{b}, \mathrm{b}}$ & $6^{\mathrm{a}, \mathrm{a}}$ & $9^{\mathrm{a}, \mathrm{a}}$ & $9^{\mathrm{a}, \mathrm{a}}$ & $0^{\mathrm{a}, \mathrm{d}}$ & $0^{\mathrm{a}, \mathrm{d}}$ \\
\hline & 6 & $6.4^{\mathrm{a}, \mathrm{a}}$ & $8^{\mathrm{a}, \mathrm{a}}$ & $9.5^{\mathrm{a}, \mathrm{a}}$ & $9.3^{\mathrm{a}, \mathrm{a}}$ & $0^{\mathrm{b}, \mathrm{d}}$ & $0^{\mathrm{a}, \mathrm{d}}$ \\
\hline \multirow{3}{*}{ LFC2 } & 2 & $2.7^{\mathrm{c}, \mathrm{d}}$ & $2^{\mathrm{b}, \mathrm{b}}$ & $7^{\mathrm{a}, \mathrm{a}}$ & $6^{\mathrm{b}, \mathrm{b}}$ & $1^{\mathrm{a}, \mathrm{d}}$ & $0^{\text {a.d }}$ \\
\hline & 4 & $3.9^{\mathrm{b}, \mathrm{b}}$ & $6^{\mathrm{a}, \mathrm{a}}$ & $7^{\mathrm{a}, \mathrm{a}}$ & $8^{\mathrm{a}, \mathrm{a}}$ & $1^{\mathrm{a}, \mathrm{d}}$ & $0^{\mathrm{a}, \mathrm{d}}$ \\
\hline & 6 & $4.7^{\mathrm{a}, \mathrm{a}}$ & $7^{\mathrm{a}, \mathrm{a}}$ & $7^{\mathrm{a}, \mathrm{a}}$ & $8^{\mathrm{a}, \mathrm{a}}$ & $0^{\mathrm{b}, \mathrm{d}}$ & $0^{\mathrm{a}, \mathrm{d}}$ \\
\hline \multirow{3}{*}{$\mathrm{LFC}+\mathrm{AJ}$} & 2 & $0.4^{\mathrm{c}, \mathrm{e}}$ & $1^{\mathrm{a}, \mathrm{c}}$ & $6^{\mathrm{a}, \mathrm{a}}$ & $7^{\mathrm{b}, \mathrm{b}}$ & $1^{\mathrm{b}, \mathrm{d}}$ & $0^{\mathrm{b}, \mathrm{d}}$ \\
\hline & 4 & $1.2^{\mathrm{b}, \mathrm{c}}$ & $1^{\mathrm{a}, \mathrm{c}}$ & $6^{\mathrm{a}, \mathrm{a}}$ & $8^{\mathrm{a}, \mathrm{a}}$ & $2^{\mathrm{a}, \mathrm{c}}$ & $0^{\mathrm{b}, \mathrm{d}}$ \\
\hline & 6 & $1.8^{\mathrm{a}, \mathrm{b}}$ & $0.7^{\mathrm{a}, \mathrm{c}}$ & $6^{\mathrm{a,a}}$ & $8^{\mathrm{a}, \mathrm{a}}$ & $2^{\mathrm{a}, \mathrm{c}}$ & $1^{\mathrm{a}, \mathrm{d}}$ \\
\hline \multirow{3}{*}{ EPSLFC } & 2 & $0.3^{\mathrm{c}, \mathrm{e}}$ & $3^{\mathrm{b}, \mathrm{d}}$ & $2^{a, c}$ & $2^{\mathrm{a}, \mathrm{c}}$ & $6^{\mathrm{b}, \mathrm{b}}$ & $4^{\mathrm{b}, \mathrm{b}}$ \\
\hline & 4 & $0.7^{\mathrm{b}, \mathrm{d}}$ & $5^{a, b}$ & $1^{\mathrm{a}, \mathrm{b}}$ & $1^{b, d}$ & $7^{\mathrm{a}, \mathrm{a}}$ & $6^{\mathrm{a}, \mathrm{a}}$ \\
\hline & 6 & $0.7^{\mathrm{a}, \mathrm{c}}$ & $5^{\mathrm{a}, \mathrm{b}}$ & $1^{\mathrm{a}, \mathrm{b}}$ & $1^{\mathrm{b}, \mathrm{c}}$ & $7^{\mathrm{a,a}}$ & $6^{\mathrm{a}, \mathrm{a}}$ \\
\hline \multirow{3}{*}{$\begin{array}{c}\text { EPSLFC + } \\
\text { AJ }\end{array}$} & 2 & $0.2^{\mathrm{c}, \mathrm{e}}$ & $0.8^{\mathrm{b}, \mathrm{c}}$ & $1^{\mathrm{a}, \mathrm{c}}$ & $1^{\mathrm{a}, \mathrm{c}}$ & $7^{\mathrm{b}, \mathrm{b}}$ & $4^{\mathrm{b}, \mathrm{b}}$ \\
\hline & 4 & $0.8^{\mathrm{b}, \mathrm{d}}$ & $0.5^{\mathrm{a}, \mathrm{c}}$ & $0.3^{\mathrm{b}, \mathrm{d}}$ & $0.5^{\mathrm{b}, \mathrm{d}}$ & $8^{\mathrm{a}, \mathrm{a}}$ & $7^{\mathrm{a}, \mathrm{a}}$ \\
\hline & 6 & $0.9^{\mathrm{a}, \mathrm{d}}$ & $0.5^{\mathrm{a}, \mathrm{c}}$ & $0.3^{\mathrm{b}, \mathrm{d}}$ & $0.5^{\mathrm{b}, \mathrm{d}}$ & $8^{\mathrm{a,a}}$ & $7^{\mathrm{a}, \mathrm{a}}$ \\
\hline
\end{tabular}

${ }^{\mathrm{a}-\mathrm{d}}$ Mean \pm standard deviation followed by the same letter's are not significant, but different letters are significant according to LSD procedure $(P<$ 0.05). ${ }^{1} \mathrm{FFC}=$ control full fat cheese made using the conventional procedure in the presence of the commercial starter culture; LFC1 = low fat cheese made using the conventional procedure in the presence of the commercial starter culture; LFC2 = low fat cheese made using the modified protocol in the presence of the commercial starter culture; LFC + Rp = low fat cheese made using the modified protocol in the presence of the commercial starter culture and the ripening cultures; EPSLFC = low fat cheese made using the modified protocol in the presence of the commercial starter culture and the EPS-producing lactobacilli; EPSLFC + Rp = low fat cheese made using the modified protocol in the presence of the commercial starter culture, the EPS-producing lactobacilli as well as the ripening cultures.

ing ripening is also observed along with the development of bitterness [9]. A slight improvement in texture characteristics was observed in the low fat cheese LFC2 manufactured using the modified protocol. The sensory evaluation of the EPS-treated cheeses revealed a significant improvement in texture characteristics, which is clearly shown in Figure 2. In fact, no significant differences in firmness were observed between FFC and cheeses made using EPS-producing cultures during the ripening period. On the other hand, FFC was found to be smoother, more crumbly and less springy than cheeses made using EPS-producing cultures after four and six months of ripening. The flavor evaluation of the different cheese samples revealed the following: LFC1 and LFC2 as well as EPSLFC samples showed an extremely pronounced bitter flavor which was detected after starting the second month of ripening. The highest levels of bitterness were detected after the fourth month of ripening. It was clearly demonstrated during this stage Lactobacillus paracasei subsp paracasei played a very effective role in reducing bitterness and improving the flavor of low fat cheese. The sensory evaluation of the different Cheddar cheeses in Table 2 revealed that EPSLFC was significantly much bitter than EPSLFC + Rp and FFC, this trend could observed during the whole ripening period. On the other hand, no significant differences in bitterness could be measured between FFC, LFC + Rp and EPSLFC + Rp can be to the debiterrase system of the ripening cultures. Adjunct treated cheeses rapidly developed the highest flavor score after three months of ripening when compared to LFC1 and LFC2. The panelist comments indicated that LFC1 and LFC2 lacked flavor after three months of ripening and with extended ripening tented to develop bitterness. Flavor scores in cheeses made with adjunct cultures were highest at 3, 4 and 6 months of ripening and tended to have higher texture scores, relatively softer body and less firmness compared to control cheeses. Many reviews studied the use of ripening cultures for the enhancement of flavor and texture in low fat Cheddar cheese [16] [29]. 
Adjunct cultures not only have a role in flavor development in ripened cheeses but may also be used to enhance functionality of low fat cheeses. Madkor, Tong, and El Soda [29] reported that adjunct culture positively influenced flavor and texture attributes in reduced fat Cheddar by preventing bitterness and reducing firmness. El Soda, Madkor, and Tong [16] demonstrated that the addition of adjunct cultures had a positive impact on low fat cheese quality and are an important contributor to the development of characteristic Cheddar cheese flavor.

In order to evaluate the Cheddar flavor quality in cheese samples we compared between the flavor of FFC Cheddar and the EPSLFC + Rp to the flavor of Cheddar cheese samples imported from Ireland and USA. The obtained data (Table 3) revealed that among all the samples evaluated the full fat cheese imported from the USA obtained the highest scores for both texture and flavor, followed by the EPSLFC + Rp. The lowest scores for both texture and flavor were obtained in the case of low fat Cheddar imported from Ireland.

\section{Conclusion}

This study has tackled the two major problems facing low fat cheese, texture and flavor. Texture defects were overcome using two strategies; a modified make procedure and the addition of two Lactobacillus strains producing exopolysaccarides. Bitterness formation was eliminated using two Lactobacillus paracasei subsp paracasei strains known for their debit erase activity. It is also believed that it is the joint action of the different microorganisms added to the cheese milk that contributed to the formation of the characteristic Cheddar cheese flavor that was comparable and is some cases preferred to the flavor of full fat cheese imported from England, Ireland and the USA. This study reveals for the first time the availability of a culture mixture capable of producing a Cheddar cheese containing $10 \%$ fat with sensory characteristics comparable to a full fat Cheddar.

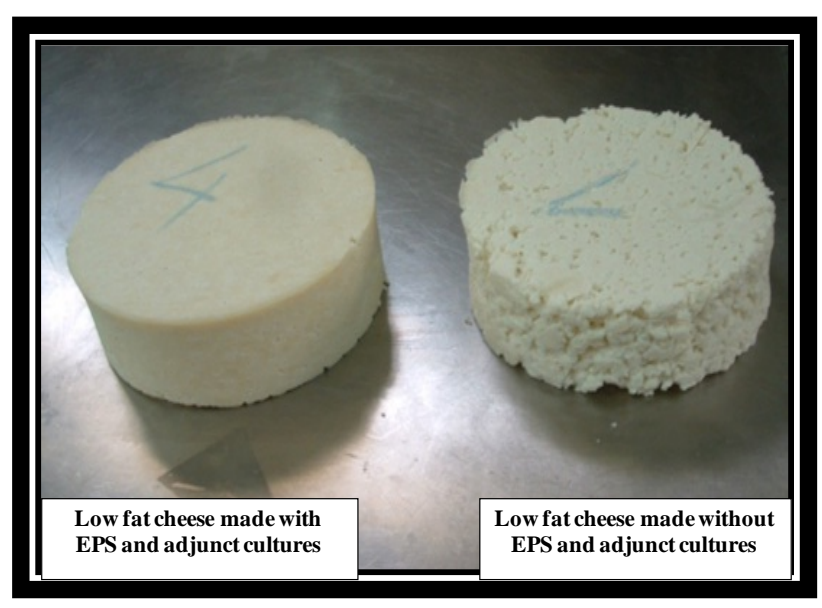

Figure 2. Low fat Cheddar cheese made with and without EPS producing cultures.

Table 3. Sensory evaluation of Cheddar cheeses ${ }^{1}$.

\begin{tabular}{|c|c|c|c|}
\hline Treatments $^{2}$ & Flavor evaluation & Texture evaluation & Cheddar notes \\
\hline FFC & $8.9^{b}$ & $8.6^{\mathrm{b}}$ & $8.5^{\mathrm{b}}$ \\
\hline $\mathrm{EPSLFC} \mathrm{+} \mathrm{AJ}$ & $8.7^{\mathrm{b}}$ & $9.4^{\mathrm{a}}$ & $8.7^{\mathrm{b}}$ \\
\hline KRAFT sharp & $9.2^{\mathrm{a}}$ & $8.9^{\mathrm{b}}$ & $9.5^{\mathrm{a}}$ \\
\hline KRAFT mild & $7.4^{\mathrm{c}}$ & $7.2^{\mathrm{c}}$ & $7.7^{\mathrm{c}}$ \\
\hline Kerrygold reduced fat & $4.6^{\mathrm{d}}$ & $3.5^{\mathrm{d}}$ & $4.3^{\mathrm{d}}$ \\
\hline CABOT Vermont & $8.8^{\mathrm{b}}$ & $7.9^{c}$ & $8.1^{\mathrm{c}}$ \\
\hline
\end{tabular}

${ }^{\text {a-d }}$ Mean \pm standard deviation followed by the same letter's are not significant, but different letters are significant according to LSD procedure $(P<$ 0.05). ${ }^{1}$ Samples were taken after four months of ripening; ${ }^{2} \mathrm{FFC}=$ control full fat cheese made using the commercial starter culture and made with the conventional procedure; EPSLFC + AJ = low fat cheese made using the commercial starter culture in addition to the two strains of the EPS-producing cultures and the two strains of the adjunct cultures and made with the modified protocol; KRAFT sharp = KRAFT Cracker barrel (sharp) imported from USA; KARFAT mild = KRAFT mild Cheddar cheese imported from USA; Kerrygold reduced fat $=50 \%$ reduced fat sharp Cheddar cheese imported from Ireland; CABOT Vermont $=50 \%$ reduced fat sharp Cheddar cheese imported from USA. 


\section{Acknowledgements}

The author would like to thank the Science and Technology Development Fund (STDF) for funding the project ID = 1009 entitled "Production of low fat Cheddar cheese made using exopolysaccharide-producing culture and selected adjuncts".

\section{References}

[1] Fenelon, M.A. and Guinee, T.P. (2000) Flavor Development in Low-Fat Cheese. In: Cogan, T.M., Ed., Proceedings of the 6th Moorepark Cheese Symposium, Teagasc, Dublin, 31-42.

[2] Dexheimer, E. (1992) On the Fat Track. Dairy Foods, 93, 38-50.

[3] Barr, A. (1990) Consumer Motivational Forces Affecting the Sale of Light Dairy Products. Food Technology, 44, 9799.

[4] Olson, N.F. and Johnson, E. (1990) Light Cheese Products: Characteristics and Economics. Food Technology, 44, 9093.

[5] Coulson, J., Pawlett, D. and Wivell, R. (1991) Cutting Fat, Keeping Flavour. Dairy Industries, 56, 31-32.

[6] Broadbent, J., Brennand, C., Jonson, M.E., Steele, J.L., Strickland, M. and Weimer, B. (1997) Starter Contribution of Reduced Fat CHEDDAR. Dairy Industries International, 62, 35, 37, 39.

[7] Emmons, D.B., Kalab, M. and Larmond, E. (1980) Milk Gel Structure. X. Texture and Microstructure in Cheddar Cheese Made from Whole Milk and from Homogenized Low-Fat Milk. Journal of Texture Studies, 11, 152-159. http://dx.doi.org/10.1111/j.1745-4603.1980.tb00305.x

[8] Jameson, G.W. (1990) Cheese with Less Fat. Australian Journal Dairy Technology, 45, 93-98.

[9] Muir, D.D., Banks, J.M. and Hunter, E.A. (1992) Sensory Changes during Maturation of Fat-Reduced Cheddar Cheese: Effect of Addition of Enzymatically Active Attenuated Cultures. Milchwissenschaft, 47, 218-222.

[10] Awad, S., Hassan, A.N. and Halaweish, F. (2005) Application of Exopolysaccharide-Producing Cultures in Reduced Fat Cheddar Cheese. Composition and Proteolysis. Journal of Dairy Science, 88, 4195-4203. http://dx.doi.org/10.3168/jds.S0022-0302(05)73105-2

[11] Awad, S., Hassan, A.N. and Muthukumarappan, K. (2005) Application of Exopolysaccharide-Producing Cultures in Reduced-Fat Cheddar Cheese: Texture and Melting Properties. Journal of Dairy Science, 88, 4204-4213. http://dx.doi.org/10.3168/jds.S0022-0302(05)73106-4

[12] Dabour, N., Kheadr, E.E., Benhamou, E., Fliss, I. and LaPointe, G. (2006) Improvement of Texture and Structure of Reduced-Fat Cheddar Cheese by Exopolysaccharide-Producing Lactococci. Journal of Dairy Science, 89, 95-110. http://dx.doi.org/10.3168/jds.S0022-0302(06)72073-2

[13] Hassan, A.N. and Awad, S. (2005) Application of Exopolysaccharide-Producing Cultures in Reduced-Fat Cheddar Cheese: Cryo-Scanning Electron Microscopy Observations. Journal of Dairy Science, 88, 4214-4220. http://dx.doi.org/10.3168/jds.S0022-0302(05)73107-6

[14] Agrawal, P. and Hassan, A.N. (2007) Ultrafiltered Milk Reduces Bitterness in Reduced-Fat Cheddar Cheese Made with an Exopolysaccharide-Producing Culture. Journal of Dairy Science, 90, 3110-3117. http://dx.doi.org/10.3168/jds.2007-0049

[15] Fenelon, M.A., Guinee, T.P. and Reville, W.J. (1999) Characteristics of Reduced Fat Cheddar Prepared from Blending Full Fat and Skim Cheese Curds at Whey Drainage. Milchwissenschaft, 54, 506-510.

[16] El Soda, M., Madkor, S.A. and Tong, P.S. (2000) Adjunct Cultures: Recent Developments and Potential Significance to the Cheese Industry. Journal of Dairy Science, 83, 609-619. http://dx.doi.org/10.3168/jds.S0022-0302(00)74920-4

[17] Robinson, R.K. and Wilbey, R.A. (1998) Cheesemaking Practice. 3rd Edition, Aspen Publication, Aspen Publishers, Inc., Gaithersburg, 352-354.

[18] Association of Official Analytical Chemists (2003) Official Methods of Analysis. 17th Edition, AOAC, Gaithersburg.

[19] Bourne, M. (1978) Texture Profile Analysis. Food Technology, 32, 62-66, 72.

[20] Szczesniak, A., Brandt, M. and Freidman, H. (1963) Development of Standard Rating Scales for Mechanical Parameters and Correlation between the Objective and Sensory Texture Measurements. Food Technology, 22, 50-54.

[21] Mistry, V.V. (2001) Low Fat Cheese Technology. International Dairy Journal, 11, 413-422. http://dx.doi.org/10.1016/S0958-6946(01)00077-2

[22] Guinee, T.P., Auty, M.A.E. and Fenelon, M.A. (2000) The Effect of Fat Content on the Rheology, Microstructure and Heat-Induced Functional Characteristics of Cheddar Cheese. International Dairy Journal, 10, 277-288.

http://dx.doi.org/10.1016/S0958-6946(00)00048-0 
[23] Costa, N.E., Hannon, J.A., Guinee, T.P., Auty, M.A.E, McSweeney, P.L.H. and Beresford, T.P. (2010) Effect of Exopolysaccharide Produced by Isogenic Strains of Lactococcus lactis on Half-Fat Cheddar Cheese. Journal of Dairy Science, 93, 3469-3486. http://dx.doi.org/10.3168/jds.2009-3008

[24] Banks, J.M., Brechany, E. and Christie, W.W. (1989) The Production of Low Fat Cheddar Type Cheeses. International Journal of Dairy Technology, 42, 6-9. http://dx.doi.org/10.1111/j.1471-0307.1989.tb01699.x

[25] Guinee, T.P., Fenelon, M.A., Mulholland, E.O., O’kennedy, B.T., O’brien, N. and Reville, W.J. (1998) The Influence of Milk Pasteurization Temperature and $\mathrm{pH}$ at Curd Milling on the Composition, Texture and Maturation of Reduced Fat Cheddar Cheese. International Journal of Dairy Technology, 51, 1-10. http://dx.doi.org/10.1111/j.1471-0307.1998.tb02631.x

[26] Johnson, M.E., Steele, J.L., Broadbent, J. and Weimer, B.C. (1998) Manufacture of Gouda and Flavour Development in Reduced Fat Cheddar Cheese. Australian Journal of Dairy Technology, 53, 67-69.

[27] Beal, P. and Mittal, G.S. (2000) Vibration and Compression Responses of Cheddar Cheese at Different Fat Content and Age. Milchwissenschaft, 55, 139-142.

[28] Creamer, L. and Olson, N. (1982) Rheological Evaluation of Maturing Cheddar Cheese. Journal of Food Science, 47, 632-636. http://dx.doi.org/10.1111/j.1365-2621.1982.tb10138.x

[29] Madkor, S.A., Tong, P.S. and El Soda, M. (2000) Evaluation of Commercial Adjuncts for Use in Cheese Ripening: 5. Effect of Added Freeze-Shocked Adjuncts Lactobacilli on Proteolysis and Sensory Quality of Reduced Fat Cheddar Cheese. Milchwissenschaft, 55, 383-386.

[30] Pastorino, A.J., Hansen, C.L. and McMahon, D.J. (2003) Effect of pH on the Chemical Composition and StructureFunction Relationships of Cheddar Cheese. Journal of Dairy Science, 86, 2751-2760. http://dx.doi.org/10.3168/jds.S0022-0302(03)73871-5

[31] Lane, C.N., Fox, P.F., Johnston, D.E. and McSweeney, P.L.H. (1997) Contribution of Coagulant to Proteolysis and Textural Changes in Cheddar Cheese during Ripening. International Dairy Journal, 7, 453-464. http://dx.doi.org/10.1016/S0958-6946(97)00041-1

[32] Kanawjia, S.K., Rajesh, P., Sabikhi, L. and Singh, S. (1995) Flavor, Chemical and Texture Profile Changes in Accelerated Ripened Gouda Cheese. LWT-Food Science and Technology, 28, 577-583. 
Scientific Research Publishing (SCIRP) is one of the largest Open Access journal publishers. It is currently publishing more than 200 open access, online, peer-reviewed journals covering a wide range of academic disciplines. SCIRP serves the worldwide academic communities and contributes to the progress and application of science with its publication.

Other selected journals from SCIRP are listed as below. Submit your manuscript to us via either submit@scirp.org or Online Submission Portal.
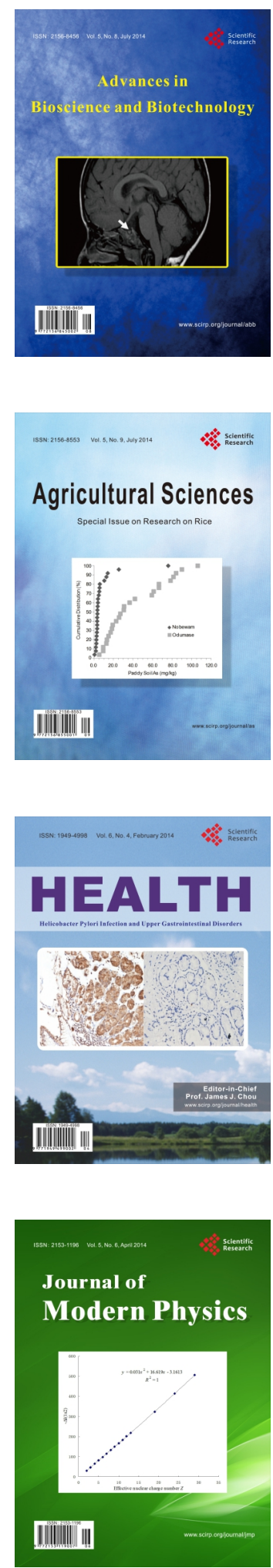
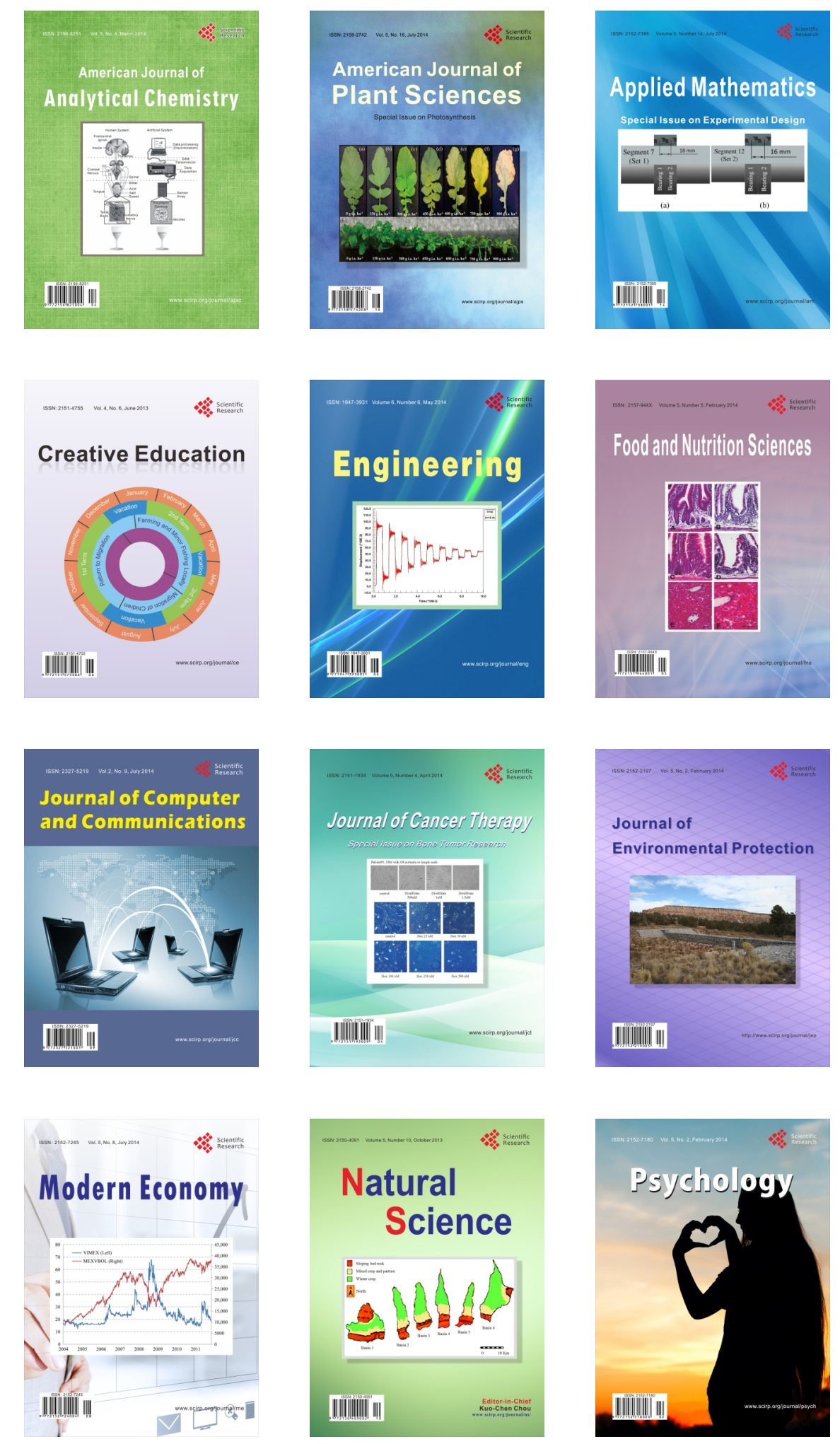